\title{
Fused Axis Vertebrae With A Third Cervical Hemivertebrae - A Rare Case Report.
}

\author{
Dr. Shweta solan \\ Department of anatomy, Kallinga Institute of Medical Sciences, Bhubaneswar, India
}

\begin{abstract}
Congenital anomalies are common in the vertebral column. Skeletal abnormalities at the cervical region may result in severe neck pain and sudden unexpected death. During the osteology demonstration of cervical vertebrae for the MBBS students, it was observed that one of axis vertebra is fused with the 3rd cervical hemivertebrae. Vertebral bodies, pedicle, lamina of $C 2$ and $C 3$ were fused on right side, while on left side, C3 lack pedicle, lamina and spine. This fused vertebrae with a hemivertebrae had embryological importance and clinical implications.
\end{abstract}

Keywords: cervical vertebra, axis, fusion, hemivertebrae, lamina, pedicle, spine

\section{Introduction}

The second cervical vertebrae acts as an axle for rotation of the atlas and head around strong odontoid process. In condition of fusion of the cervical vertebrae (FCV), two vertebrae appear as one.This fusion may be congenital or acquired This anomaly may be asymptomatic , or may also appear with manifestations of serious clinical features such as myelopathy or may be associated with syndromes such as Klippel-feil , limitation of the neck movement, or the muscular weakness, atrophy and neurological sensory loss ${ }^{2}$. Hemivertebra is a rare congenital spinal malformation, where only one side of the vertebral body develops, resulting in deformation of the spine, such as scoliosis, lordosis, or kyphosis. ${ }^{3}$

\section{Case Report}

During the osteology demonstration of cervical vertebrae for the MBBS Phase I students at Kallinga institute of medical sciences, it was observed that the axis vertebrae was fused with 3rd cervical vertebra which was a hemivertebrae. The features of this fused axis and 3rd hemi cervical vertebrae was analyzed and the specimen was photographed from different aspects.

\section{Observations:}

-C3 had body that was fused with body of axis completely on both anterior and posterior aspects.

.On right side, $\mathrm{C} 3$ had pedicle, transverse process with foramen transversarium, laminae and spine. Out of them, only laminae was fused.

.on left side, $\mathrm{C} 3$ has only vertebral body. It lacks lamina, spine, pedicle and transverse process.

-foramen transversarium are present in both $\mathrm{C} 2$ and $\mathrm{C} 3$ on right side, while on left side, it is present in $\mathrm{C} 2$ only.

The diameter in $\mathrm{C} 2$ on the left side measured $4.73 \mathrm{~mm}$ and on right side $4.78 \mathrm{~mm}$.

The diameters were measured from superior aspect in $\mathrm{C} 2$ and from the inferior aspect in $\mathrm{C} 3$.

\section{Figures}

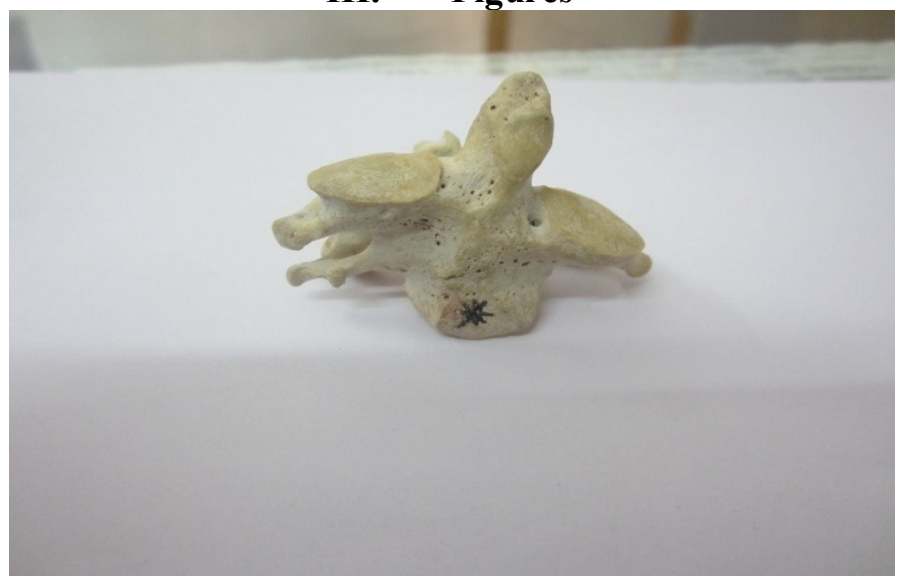

Figure-1- Showing fused C2 with $\mathrm{C} 3$ hemivertebrae.[ ventral view].On right side, two pedicle and transverse process, while on left side one pedicle and transverse process. 


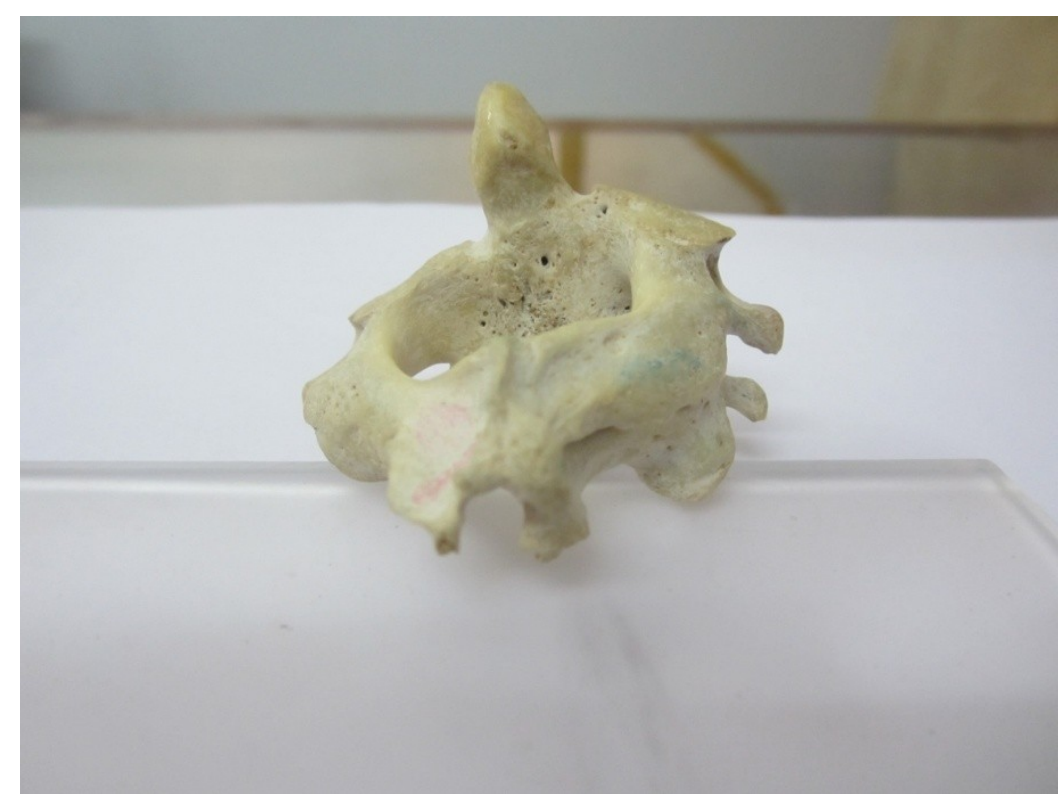

Figure-2- Showing two pedicle,two transverse process with foramen transversarium, single fused lamina and two spines on right side.

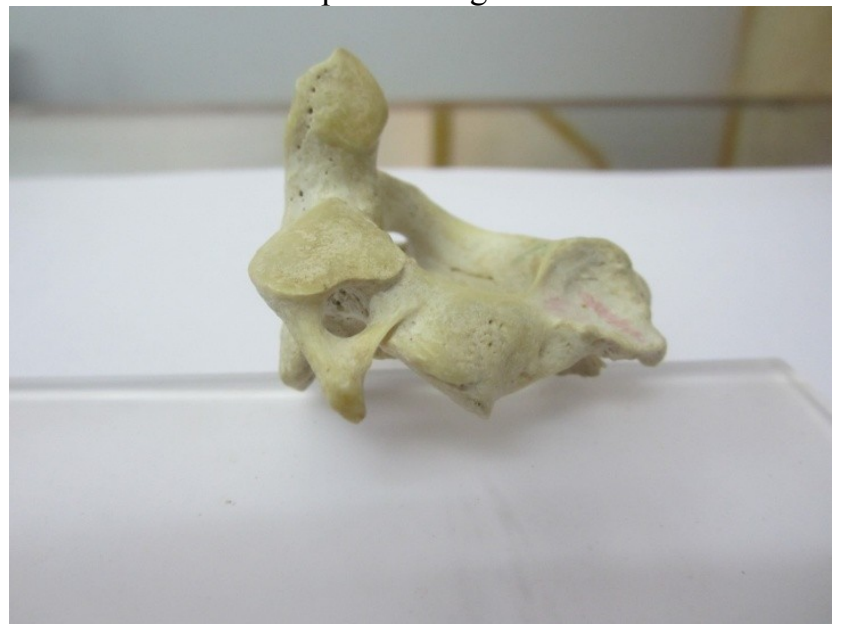

Figure-3- Showing single pedicle, transverse process with foramen transversarium,lamina and spine on left side.

\section{Discussion}

Fusion of one or more contiguous vertebral segments results from the embryological failure of normal spinal segmentation. This most likely is the result of a local decreased blood supply during the third to eighth week of fetal development. $\mathrm{C} 2-\mathrm{C} 3$ is the most common site, and the incidence is $0.4 \%$ to $0.7 \%$ with no sex predilection. ${ }^{4}$ Fused cervical vertebrae (FCV) have clinical and embryological importance. The anomalies of cervical region are of interest to anatomists, orthopedists, neurologists, neurosurgeons and even orthodontists. In FCV two vertebrae appear both structurally and functionally as one. This fusion may be congenital or acquired. ${ }^{2}$ Patients are generally asymptomatic, but increasing age and injury may precipitate symptoms. Premature degenerative changes at adjoining motion segments are common as this condition results in greater biomechanical stress in the adjoining segments. Discal tear, rupture of the transverse ligament, fracture of the odontoid process, and spondylosis are common consequences. ${ }^{4}$ It may be associated with tuberculosis, other infections, juvenile rheumatoid arthritis and trauma; or Klippel-Feil syndrome. ${ }^{2}$

Hemivertebra is a rare congenital spinal malformation, where only one side of the vertebral body develops, resulting in deformation of the spine, such as scoliosis, lordosis, or kyphosis. ${ }^{3}$ The cause of hemivertebra is unknown.It may result from abnormal distribution of the intersegmental arteries of the vertebral column ${ }^{5,6}$.It is frequently associated with other congenital anomalies like diastematomyelia,cardiac and genitourinary tract anomalies. . Hemivertebra may be part of syndromes including Jarcho-Levin syndrome, Klippel-Fiel syndrome, VATER syndrome (vertebral anomalies, imperforate anus, tracheoesophageal fistula, and renal anomalies), VACTERL syndrome (VATER with cardiac and limb anomalies), OEIS (omphalocele, bladder extrophy, imperforate anus, and spine anomalies), the Potter sequence, and open spina bifida. ${ }^{7}$ Among 
the congenital vertebral anomalies, hemivertebrae are the most likely to cause neurologic problems. Neurologic signs result from severe angulation of the spine, narrowing of the spinal canal, instability of the spine, and luxation or fracture of the vertebrae. Signs include rear limb weakness or paralysis, urinary or fecal incontinence, and spinal pain. ${ }^{8}$ Most cases of hemivertebrae have no or mild symptoms, so treatment is usually conservative. Severe cases may respond to surgical spinal cord decompression and vertebral stabilization. ${ }^{9}$

\section{References}

[1]. Susan Standring, ed. Gray's Anatomy. 40th Ed. Elsevier Churchill Livingstone. 2008; 720-721.

[2]. Erdil H, Yildiz N, Cimen M. Congenital fusion of cervical vertebrae and its clinical significance. J Anat Soc India. 2003; 52: 125-127. Michail Varras, Christodoulos Akrivis.Prenatal diagnosis of fetal hemivertebra at 20 weeks' gestation with literature review.Int J Gen Med. 2010; 3: 197-201.

[4]. Soni P, Sharma V, Sengupta J. Cervical vertebrae anomalies-incidental findings on lateral cephalograms. Angle Orthod. 2008; 78 : 176-180.

[5]. Tanaka T, Uhthoff HK. The pathogenesis of congenital vertebral malformations. A study based on observations made in 11 human embryos and fetuses. Acta Orthop Scand. 1981;52:413-425. [PubMed]

[6]. Forrester MB, Merz RD. Descriptive epidemiology of hemivertebrae, Hawaii, 1986-2002. Congenit Anom. 2006:4617246176. [PubMed

[7]. Wax JR, Watson WJ, Miller RC, et al. Prenatal sonographic diagnosis of hemivertebrae - associations and outcomes. J Ultrasound Med. 2008;27:1023-1027. [PubMed]

[8]. Braund, K.G. (2003). "Developmental Disorders". Clinical Neurology in Small Animals: Localization, Diagnosis and Treatment. Retrieved 2007-02-04.

[9]. Jeffery N, Smith P, Talbot C. "Imaging findings and surgical treatment of hemivertebrae in three dogs". J Am Vet Med Assoc. 2007;230 (4): 532-6. 